\title{
Adaptive Institutions? Peasant institutions and natural models facing climatic and economic changes in the Colombian Andes
}

Article

Accepted Version

Creative Commons: Attribution-Noncommercial-No Derivative Works 4.0

Feola, G. (2017) Adaptive Institutions? Peasant institutions and natural models facing climatic and economic changes in the Colombian Andes. Journal of Rural Studies, 49. pp. 117127. ISSN 0743-0167 doi:

https://doi.org/10.1016/j.jrurstud.2016.10.007 Available at https://centaur.reading.ac.uk/68365/

It is advisable to refer to the publisher's version if you intend to cite from the work. See Guidance on citing.

To link to this article DOI: http://dx.doi.org/10.1016/j.jrurstud.2016.10.007

Publisher: Elsevier

All outputs in CentAUR are protected by Intellectual Property Rights law, including copyright law. Copyright and IPR is retained by the creators or other copyright holders. Terms and conditions for use of this material are defined in the End User Agreement. 


\section{CentAUR}

Central Archive at the University of Reading

Reading's research outputs online 


\title{
Adaptive Institutions? Peasant institutions and natural models facing climatic and economic changes in the Colombian Andes
}

\author{
Giuseppe Feola \\ Department of Geography and Environmental Science, University of Reading, Whiteknights, RG6 6AH, Reading, \\ United Kingdom. \\ g.feola@reading.ac.uk
}

\begin{abstract}
In the Colombian Andes, peasants have co-evolved with their environment for centuries, but it is uncertain whether traditional informal institutions and natural models are adapting to current and possibly unprecedented economic and climatic disturbances. This study investigated institutional adaptation and the social mechanisms of institutional change or continuity among peasants in the Eastern Andean Cordillera. The research was informed by evolutionary theories of institutional change and based on a qualitative approach that included data collected through a focus group, oral histories, key informant interviews and observations. This study suggests that reciprocal work exchanges, festivities and gender-based divisions of roles have been disused or changed due to economic pressures, but that most informal institutions have persisted due to selective outmigration, conformist intergenerational transmission, and practices of everyday resistance. The natural model of vital energy and the traditional peasant ethos represents a 'social attractor' that has influenced institutional continuity. This study highlights tensions between resilience, cultural diversity, and transformation that are important in many other marginal rural locations in the Andes. Future research should further explore first, under what conditions institutional adaptation is observed and when it is related to increased resilience, and, second, how transformability, socialecological resilience and cultural diversity are related.
\end{abstract}

\section{Keywords}

Adaptive institutions, Cultural change, Peasant, Colombia, Climate change, Trade liberalization 


\section{Introduction}

In the Colombian Andes, peasants have co-evolved with their environment for centuries, but it is uncertain whether traditional informal institutions and natural models are adapting to current and possibly unprecedented economic and climatic disturbances. This study investigated institutional adaptation and the social mechanisms of institutional change or continuity among peasants in the Eastern Andean Cordillera.

The future of Colombian peasantry in the face of current climatic and economic changes is the object of intense debate. Experts have observed climate change and increased climate variability in Colombia, and peasants are believed to be among those most disproportionately vulnerable to the projected changes (Feola et al., 2015a). Some have proposed that a lack of knowledge of technical and economic means most determines capacity to adapt, (Ramirez-Villegas et al., 2012; DNP-BID, 2014). Others have suggested that legacy issues such as marginalization, unequal access to land, violent conflict, and more recent concerns on land use conflicts (e.g. between mining and agriculture) and trade liberalization have led to the problem (Forero, 2010; Cárdenas and Rodríguez, 2013; Feola, 2013; Feola et al., 2015a). Many argue that this last concern-trade liberalization, specifically as a mechanism of integration of peasant communities in global economic structuresnegatively affects rural communities' adaptive capacity and magnifies vulnerability (Eakin, 2005; Young and Lipton, 2006; Ribot, 2011; Wilson, 2012).

Successive Colombian governments have consistently employed trade liberalization policies, together with market-led agrarian reform, to achieve agricultural modernization. However, trade liberalization often clashes with peasants' traditional institutions, and farming practices, such as reciprocal systems of exchange and altitudinal zonation (Mayer, 2002; Stadel, 2008), which have historically guaranteed agricultural adaptation to the Andean environment. Trade liberalization is a form of forced cultural and productive transformation (Feola, 2015) that often reinforces the 
marginalization of non-commercial farmers who are outcompeted on globally exposed markets (Petras and Veltmeyer, 2002). This approach to rural development has led to collective protests in Colombia that paralyzed the country in 2012 and 2013 (Cruz, 2014; see also Hristov, 2005).

Other research of Andean peasants paints a picture of successful adaptation in both historical and current times. Various authors show that traditional informal institutions have persisted or reemerged in the face of increased climate risk and market liberalization. For instance, sharecropping and reciprocal labour exchanges facilitate peasant access to more diverse land, inputs, and labour, and allows them to co-exist with liberalized agricultural markets (Arias, 2005; Espinosa, 2009). Bartering and exchanging goods and labour helps reduce climate risk (De los Rios and Almeida, 2010). Thus, modern and traditional institutions can coexist in 'hybrid cultures' (Escobar, 1995; see also Cleaver, 2001) through complex dynamics of institutional and cultural change.

Authors have examined institutional change and adaptation in the resilience and governance literature (Boyd and Folke, 2012; Agrawal et al., 2008, 2013), which has highlighted important theoretical gaps. First, research has focused mostly on the outcomes of particular institutional systems, but has largely overlooked how these systems came to exist in their current form (David, 1994; Ternström, 2012). Other authors posit that traditional institutions are not static and brittle, but are in fact quite dynamic systems of norms (Cleaver, 2001; Raynaut, 2001; Tengö and Von Heland, 2012); ultimately, there is a lack of understanding of how institutions adapt to a range of disturbances (Boyd and Folke, 2012).

Much research has focused on formal institutions, rather than informal ones (Young et al., 2008, Casson et al., 2009). Considerable gaps still exist with respect to our understanding of informal institutions, and the mechanisms through which they can develop outcomes and adaptation (Cleaver, 2001; Jüttings et al., 2007; Casson et al., 2009; Cleaver, 2012; Forsyth and Evans, 2013). 
Other environmental change research has focused on environmental institutions (e.g. common property regimes), but non-environmental institutions-those not directly aimed at environmental governance, such as labour exchange, or barter-can more significantly influence humanenvironment interactions (Cleaver, 2012). Several authors argue that more research should be devoted to understanding the environmental performance of non-environmental institutions in adaptation to climate change (Mitchell, 2008; Underdal, 2008).

This study seeks to fill these gaps by investigating the peasant settlement of Las Cañas in the Colombian Andes. Particularly, this study investigates institutional adaptation, or a lack thereof, and the social mechanisms of institutional change, or continuity. This study asks whether and which informal institutions and connected natural model are changing or persisting in response to climatic and economic disturbances, and how change, or continuity, has occurred.

The findings of this study will increase scholars' understanding of peasants' adaptation in the Colombian Andes and contribute to the growing body of scholarship on the mechanisms of institutional adaptation and cultural change.

The paper is structured as follows. Section 2 briefly reviews the literature on institutional change, and particularly it presents evolutionary theories and theories of institutional continuity that inform this study. Section 3 presents the research methods adopted for this study, while the following section describes the informal peasant institutions and related natural model that were object of study. Section 5 describes the study area of Las Cañas, namely its biophysical, demographic and socio-economic characteristics and recent trends that provide the necessary context to the understanding of institutional change and continuity in this area. Section 6 presents the study's findings and discusses them in the light of the literature on institutional change. Finally, section 7 summarizes the main findings and identifies relevant questions for future research on the relation between institutional adaptation and cultural diversity. 


\section{Theoretical context}

Several competing definitions of institutions exist, but it is out of the scope of this paper to comprehensively review such definitions. For the purpose of this paper, institutions will be defined as the "humanly devised constraints that structure political, economic and social interaction" (North, 1990:97). Institutions constrain and enable action by assigning power, rights, obligations, and giving a reason for action, based on collectively shared systems of meaning (Searle, 2005; Aoki, 2007).

Institutions can be formal-laws, normally codified and enforced by specialised actors-or informal-reciprocal exchange, normally not codified and enforced endogenously by members of the relevant group-and create behavioural expectations that facilitate coordination and reduce uncertainty (North, 1991; Kingston and Caballero 2008). At their best, institutions simplify problems and reduce the transaction cost of societal decision-making (Wegerich, 2001). Institutional effectiveness rests on institutions being perceived as objective facts taken for granted by social actors (Taussig, 1980; Aoki, 2007; Kingston and Caballero, 2008).

Institutions change over time. Kingston and Caballero (2008) discuss two groups of institutional change theories: collective choice and evolutionary change theories (see also Jüttings et al., 2007). While institutional change may occur through a combination of collective choice and evolutionary processes (Poteete, 2014) and evolutionary theories do not rule out collective decision-making processes as sources of institutional selection (Dietz and Burns, 1992), this distinction allows researchers to isolate some important differences in the sources of institutional change for different types of institutions.

Collective choice theories conceptualise institutional change as a centralised and explicit process led by a specialised entity that sets the rules within which individuals and organizations engage (Kingston and Caballero, 2008). Contextual changes may shift the benefits for the actors involved in collective action, which triggers learning processes and the need to change the 'rules of the game.' 
Power relations and vested interests may steer institutional change towards institutions that result in inefficient outcomes, or hinder institutional change (Kingston and Caballero, 2008). Collectivechoice theories of institutional change have made important contributions to understanding formal institutions, but inadequately explain informal institutions. Informal institutions appear to have evolved in a decentralised fashion with little apparent effort to design a set of rules (Dietz and Burns, 1992).

For these reasons, evolutionary change theory is better suited to study the change process of informal institutions. These theories conceptualise institutional change as an evolutionary process, or one defined by the mechanisms of variation, selection, and inheritance (Kingston and Caballero, 2008). New institutional variations emerge from the uncoordinated actions of multiple actors (Kingston and Caballero, 2008), and in different ways, including chance, interpretation of existing rules, and error (Dietz and Burns, 1992). Variations can then be selected through various processes, which Burns and Dietz (1992) name p-selection, s-selection and m-selection. P-selection corresponds to the usage of power-to sanction or incentivise diversion from existing norms; s-selection refers to social structures, as a result of intended, or unintended, structural design, usually by elites; and mselection refers to the response of the material environment to human action, which makes human activity impossible in a particular environment based on certain rules.

Some evolutionary approaches assume that institutional change originates from exogenous factors such as new information about the world, or a change in material conditions-a technical change (Mitchell, 1988; Wegerich, 2001). However, other scholars highlight the importance of endogenous selection processes. Existing institutions may determine the selection of institutional variations by influencing social goals (what is socially valuable), and by influencing the acceptability of the variations, whereby variations incoherent with a belief system will be less acceptable and therefore less likely to spread (Dietz and Burns, 1992). Institutional change may be decoupled from material 
advantage and be totally dependent on the dynamics of meanings and symbols (Dietz and Burns, 1992).

Other authors have focused on institutional continuity. For example, Aoki (2007) argues that institutions do not exist in isolation, but are interlinked in institutional systems, which scale up the challenge of institutional change from a single institution to a more complex and possibly resistant system of norms. Similarly, Dietz and Burns (1992) argue that institutional variations must be consistent within existing meta-rules to be accepted, and that the level of resistance may depend on the level of institutional integration. Furthermore, Dietz and Burns (1992) and Ostrom et al. (1994) identify different normative levels-operational, collective-choice, and constitutional-and identify that deeper level norms are more difficult to change. The monetary, cognitive, or symbolic costs of change (Wegerich 2001), and conformist transmission in groups that face heterogeneity (Burns and Dietz, 1992) have also been highlighted as possible sources of institutional continuity.

Douglas (1986) proposes that social institutions are inherently linked to natural models, which provide a fundamental representation of the world. Such a representation allows an evaluation of the desirability or appropriateness of a particular institution, or its consistency with a particular understanding of the world. Furthermore, von Heland and Folke (2014) show that natural models legitimise particular institutions by 'naturalizing' those humanly devised constraints through the analogy with the supposedly indisputable physical or supra-natural world. Therefore, they validate and legitimise institutions in situations of crisis -ineffectiveness or lack of fit - thus inhibiting change (Douglas, 1986). This resonates with the concept of 'social attractor' employed by Abel et al. (2006) and von Heland and Folke (2014), each of whom showed how culture can steer the system towards a particular stable point, and thereby hinder change to a different social basin. In other words, institutions embody the memory of a social system, which can constrain change (David, 1994, Wilson 2012), and which, especially when institutions are tightly integrated and homogeneous, make some institutional variations appear unthinkable, and others natural (Dietz and Burns, 1992). 


\section{Method}

This study investigated institutional adaptation, or a lack thereof, and the social mechanisms of institutional change, or continuity. This study posed two main questions. Firstly, it asked whether and which informal institutions and connected natural model were changing or persisting in response to climatic and economic disturbances. Secondly, this study asked what processes have led to institutional change, or continuity in the face of external (i.e. contextual) economic and climatic changes. The identification of the informal institutions and natural model that were object of the study was based on the existing literature (see following section), while the identification and examination of the processes that resulted in change or continuity was informed by evolutionary theories and theories of institutional continuity briefly described in the previous section.

Institutions only exist from the point of view of social actors (Searle, 2005) and in order to understand informal institutions from the peasant's perspective, a qualitative research approach was adopted. Furthermore, as suggested by Escobar (1995), qualitative and ethnographic approaches allow for a closer understanding of how development is experienced and resisted. Indeed, development, in the form of trade liberalization and rural development interventions, was hypothesised to exert substantial influence on informal institutions. Ternström (2012) posits that major recent disturbances constitute historical moments on which one can trace the effects of these changes on social institutions. Jackson and Russell (2010) believe life histories can help gain an awareness of the 'everyday' as temporally and spatially embedded. Life histories elicit memory, which is understood as an active process of creation of meaning and construction as part of an ongoing explanatory and relational process. For these reasons life histories were used, alongside other methods, in this study.

Secondary data included statistical datasets available from the Colombian National Statistical Office, and background land use and health service planning documents of the City of Sogamoso. 
The data collection for this study was divided in two fieldwork phases that took place in AugustSeptember 2013, and July-August 2014, for a total of 9 weeks. The data collection methods employed in the two phases respectively are summarised in Table 1.

Table 1. Data collection methods employed in this study.

\begin{tabular}{ll}
\hline Field work phase $\mathbf{1}$ & Field work phase $\mathbf{2}$ \\
\hline 1 focus group with 8 peasants & 6 interviews with 7 peasants (1 couple) \\
1 interview with 1 out-migrant & 1 focus group with 3 key informants \\
5 key informant interviews & 2 interviews with 3 out-migrants (1 couple) \\
Observation in field visits & 1 key informant interview \\
Secondary data and historical literature & Observations in field visits \\
& Secondary data and historical literature \\
\hline
\end{tabular}

The selection of the study area, vereda Las Cañas, and access to both the local residents and the key informants was facilitated by a local non-governmental organization (NGO) called Jischana Huitaca, and one out-migrant currently living in the nearby city of Sogamoso. This allowed for building a more trusted interviewer-interviewee relationship. All participants were informed of privacy and ethics practices, and their informed consent to participate in the research was secured. The study area was selected for its relative remoteness, its difficulty to adapt to economic and climatic disturbances, and the pre-existing contacts between Jischana Huitaca and the local residents (see following section). Access to all peasants participants was obtained via Jischana Huitaca and snowball sampling and all key informants recommended by Jischana Huitaca as knowledgeable of the study area were interviewed. Data from secondary sources, observations focus groups, key-informant interviews and semi-structured interviews with peasants were triangulated (Feola et al., 2015b) to build confidence in the data. 
The first field work phase included a focus group with eight peasants, which allowed the researcher to collect data on basic household economic characteristics, and to explore the role of informal institutions regarding themes pre-identified by the researcher, namely: experience of economic change, experience of climatic change and variability, and generational relations. Five key informants were interviewed. The key informants were professionals who at the time worked, or had worked, in Las Cañas and surrounding region, and therefore were expected to provide a privileged, albeit inevitably partial, perspective on the study area. The key informant interviews were semi-structured interviews that covered the following themes: livelihood, lifestyles and lifestyle modernization, the experience of the free-trade agreements, in- and out-migration, experience of extreme climatic events and of climatic variability, and formal institutions. The household interviews addressed the same themes, and additionally elicited the life histories related to extreme climatic events, and economic changes). The interviews lasted between 30 minutes and 1 hour and 7 minutes.

The second fieldwork phase built on the preliminary findings of the first phase and involved six interviews (three males, two females and one couple), which allowed the collection of in-depth data on the themes addressed in the focus group in the first fieldwork phase. One key informal interview with the only local shop keepers was also carried out by using the same protocol used for key informant interviews the previous year. Finally, three interviews with permanent out-migrants from Las Cañas (two female, one couple) were conducted in the city of Sogamoso, which is the main destination for out-migrants from Las Cañas.

All interviews and the focus group were digitally recorded and subsequently transcribed. Latent content analysis of the interview transcripts and focus groups was carried out by means of coding supported by the NVivo software (qsrinternational.com) to unveil institutional change or continuity and the underlying social processes. The transcripts were complemented by a personal and an analytic log (Hay, 2010), which recorded the data from observations and field visits. The transcripts 
were analysed in Spanish, which is the peasants' mother tongue, and a language in which the researcher is proficient, controlling for potential loss of meaning due to translation errors.

\section{Informal Institutions and natural models in the Colombian Andes}

Following Douglas (1986) this study focussed on both institutions, namely informal peasant institutions, and the natural model that legitimize them. Specifically this study focussed on informal peasant institutions and related natural models in the Colombian Andes. The selection of the specific institutions and natural model to be studied was guided by the vast existing literature on Andean peasants (e.g. Mayer, 2002; Stadel, 2008; Peralvo et al., 2010) and Colombian Andean peasants in particular. This section outlines the natural model of vital energy and the informal institutions that it supports (Table 2), both of which represent the object of this study. The natural model of vital energy is an ideal type and as such it captures peasant's cultural basis, but may not be fully expressed in everyday life, giving up room for contradictions and exposure to other cultural influences. The recognition that the model of vital energy is an ideal type, and a cultural construct in itself, was fundamental to prevent essentialising the natural model and peasant ethos.

Shanin (1973) and Forero (2013) refer to peasantry as a group whereby the "family farm as the basic multi-functional unit of social organisation, land husbandry and usually animal rearing as the main means of livelihood, a specific traditional culture closely linked with the way of life of small rural communities and multi-directional subjection to powerful outsiders" (Shanin, 1973:63-64)

\subsection{The natural model: vital strength}

The household is the fundamental unit of social organization of Colombian peasantry, which is similar to what is observed in the broader Andean region. Most traditional informal institutions are defined around the function of the household, and structure resource access and distribution, 
organization of production, and labour mobilization around that (Fals-Borda, 1955; Comerci, 2012; Forero, 2013).

According to Gudeman and Rivera (1990) and Gudeman (2012), the house is a model of the economy, and, like a physical house, is a closed unit that needs to be maintained. Similar to what is observed in other Andean countries (Sarmiento et al., 1993 in Venezuela), peasants form the base of the house, its foundations. They act as much more than its physical foundations, however and in fact form the wealth or strength of the house. The strength (fuerza), or vital energy, is the energy that people use in daily life, and that crops, land, animals, and objects embody. The vital energy flows cyclically from crops, to animals, to and between people through labour and through labour back to the physical environment-the vital energy is the current of the economy and of life (Gudeman, 2012).

In this natural model, the vital energy cannot be created, but is conveyed by people, who secure it, transform it and remake it. Peasants "have a conservation, organization, and entropic notion of force or vital energy. For example, according to their model, the strength in soil, water, and wind is preserved as it passes to crops and then to humans, who assemble and use it up in living and, by planting new crops, help to compose more strength" (Gudeman, 2012, 5). Peasants "see wealth in terms of a cycle that is naturally limited and must be carefully managed. They occupy a humble position in their economic model that assumes limits to accumulation" (Gudeman, 2012, 5).

The household's goals are to maintain itself and to increase the base; due to the cyclical nature of the vital energy flow, these goals are never really reached. Rather, they represent a way of life and are "always in the making" (Gudeman and Rivera, 1990).

Peasants take care of the flow of energy by being thrifty and making savings. The focus of thriftiness is the materiality of objects and the physical environment-its use value-not the financial value 
(see also Sarmiento et al., 1993; Rist, 2000). The sustainability, or reproduction of the household, can only be achieved through caution and by making savings (Gudeman and Rivera, 1990).

The current of vital energy is therefore material, but it is also relational, in that it connects people and the physical world in circular relations. The vital energy connects households, people, and the physical environment (Mayer, 2002; Forero, 2013). Within the household, men and women support each other by joining their strength to reproduce the household, although the division may differ between men's and women's tasks. More than a market contract or a pure exchange situation, shared strength establishes relations that ground the social institutions of the household. Similarly, between households, the flow of vital energy sustains forms of reciprocal labour exchange such as the mano vuelta (returned hand), and of goods such as in barter type exchanges (De los Rios and Almeida, 2010). In these cases it is more than labour that is exchanged; it is also the flow of strength that is ensured and passed through households to increase their base (Gudeman, 2012). Reciprocity, being a non-monetary transaction, allows for savings and therefore for maintaining or increasing the household's base. Similarly, temporary labourers are traditionally paid in-kind (e.g. through a part of the harvested crop), and this is a way to return the strength put in the work and to make savings. Festivities are a waste of the base in that they entail an exceptional expense of accumulated base. However, festivities represent a way to share the base, identity and vital energy with others for connection and future recognition. Therefore, a failure of a household to participate in reciprocity "is a killing force, which is as much a part of reciprocity's meaning as life's vitality shared" (Gudeman, 2012, 15).

The household economy exists within political and legal frameworks and within a market system to which it is connected for the purchase of inputs (Forero, 2010). However, the peasant household is at the margin of the market, and the peasant economy is a material, not a financial economy; money is used as mean of exchange inside and outside the home to transfer goods, not to make monetary gains (Gudeman and Rivera, 1990). 


\subsection{The peasant ethos}

In a landmark study of peasantry in Boyacá, Fals-Borda (1955) identified the peasants' traditional ethos. Fals-Borda identified a Weltanschauung based on the centrality of agriculture and conservatism, which resulted in a "stubborn passivity and resignation" and "unshakable pattern of conservatism and austerity" (1955). In Fals-Borda's analysis, the peasant ethos was characterized by a reserved nature and distrust of novelty. Peasants were described by Fals-Borda as defensive, accepting unquestioned tradition, and satisfied with low standards of living (i.e. embracing sufficiency and austerity). While the literature on poverty and development has long debated the connections between such cultural and other structural explanations of low livelihood levels (Small et al., 2010), similar characteristics of the peasant ethos, for instance enduring hardship (aguantar), have been recognized among peasants in other Andean countries (Mayer, 2002). These cultural traits may or may not cut across gender or intergenerational divides.

In his analysis, Fals-Borda explains the peasant ethos as coming from a century-long history of exploitation in colonial and post-colonial times, which caused a deeply rooted distrust of the external world. Peasants developed this ethos as a defence against exploitation, and religious and political organizations had encouraged a passive ethos to facilitate social control. The sparse settlement model (granja aislada) that is characteristic of the Colombian Andes reinforces individualism and centeredness around the household and the family (Fals-Borda, 2006). This settlement model characterises indigenous populations and has persisted during the colonial period despite the attempt of the colonial authorities to establish more aggregated and ordered settlements. In post-colonial time, the civil conflict that plagued Colombia drove many residents of urban and rural centres to look for refuge in remote and hidden places in the countryside, thus reinforcing the existing sparse settlement pattern (Fals-Borda, 2006). 
Fals-Borda's description of the peasant ethos is consistent with that of Gudeman and Rivera (1990) and Gudeman's (2012) work on the natural model of vital energy. Although these authors did not refer specifically to a peasant ethos, when describing the natural model of vital energy they discussed the character of peasant ethos that accompanies the natural model, and it largely corresponds to Fals-Borda's description. They identify traits such as sufficiency and austerity; an absence of a desire to make monetary gains; the propensity to thrift, all motivated by the presumption that the flow of strength is limited, in contrast with the assumption that wealth grows and expands. They also identify the capacity to endure hardship, which is grounded on a concept of life as a struggle to keep the vital energy flowing; this struggle is unending and the flow is cyclical, rather than being short-term and linear. Finally, Gudeman and Rivera (1990) recognised the apparently fatalistic acceptance of uncertainty in contrast with modern aspirations of the control of the physical environment, whereby the vital energy is never created, but given by God in the first instance and therefore entails and element of 'luck'.

Thus, the peasant ethos represents a 'way of being' which accompanies the 'way of doing' structured by informal institutions. Both the ethos and the informal institutions are sustained by the natural model of vital energy.

\section{Case study Vereda Las Cañas}

The study was conducted in the vereda (settlement) of Las Cañas, in the Region of Boyacá, Province of Sugamuxi, in the eastern Andean Cordillera. It is a mountain area located at $3050-3700$ masl (POT Sogamoso 2014) and at about $34 \mathrm{~km}$ from the provincial capital of Sogamoso.

Las Cañas is a sparse settlement of about 30 households (ca. 150 residents), containing one primary school, one health centre staffed one day per month, and one grocery shop. Police forces are mostly non-existent, and responses to emergencies were often slow or absent. Transport infrastructure 
within Las Cañas was poor and essentially consisted of two clay roads that converged on the main road that connects the cities of Sogamoso and Yopal. Travel time from Las Cañas to Sogamoso by public transport took a minimum of 45 minutes, but waiting times for the intermittent public transport could be as long as three hours. Most households did not possess any motorised private transport, and only few had a small motorcycle. People moved around within Las Cañas mostly by foot.

The majority of terrain in Las Cañas is steep and not appropriate for mechanization, and farmers were dependent on the rain cycles for production. Two creeks run through the area, but they were not used for irrigation due to the lack of irrigation devices. There are two rainy seasons namely March-September and October-February, although some participants noted extreme eventsdroughts - and variable precipitation and frost patterns occurring more frequently (focus group, interview 15), which is possibly to be attributed to increased climate variability and change (Feola et al., 2015a). This is consistent with what has been observed in other rural areas in Colombia, where farmers have noted a mismatch between the traditional agricultural calendars and their observations (interviews 2, 15). Soil quality in Las Cañas is uneven, with residents reporting varied observations regarding soil fertility (focus group and interviews 9, 11). Two strong El Niño events in 2010 and 2011 caused extreme drought followed by flooding, and coincided with a substantial wave of outmigration (interview 11).

The two creeks in the vereda originate in the highest part of the study area, which is an official conservation area of the highly biodiverse, high-mountain páramo ecosystem (Páramo de Siscunsí). This conservation area attracted visitors from Sogamoso, Bogotá, and other cities. These visitors tended to have limited direct contact with the local population, since they accessed the páramo by small private buses. The establishment of the conservation area entailed dispossession of communal land. The ban to access lower páramo territories for livestock grazing, in the face of allowing tourist access for recreation and fishing, was negatively perceived by peasants, who also complained about 
the perceived environmental impact of recreational activities for which they did not receive any compensation. Residents of Las Cañas have not received governmental support for developing tourist services, to complement their income from agriculture (focus group, interviews 4, 10, 14, 16). The conservation area employed one person from Las Cañas as a ranger, but payment was intermittent (interview 13). Further programs for the conservation and reforestation of waterfronts have been proposed and implemented by the regional agency for sustainable development (Corpoboyacá). This has generated further disappointments among local residents, due to their restricted access to productive land, the lack of consultation, and the lack of consideration of local and traditional knowledge in the process (interviews 8,12 ). While the process appeared to have been approved with the locals (focus group), they have not received adequate monetary compensation for the dispossessed land since the original owners received cadastral, rather than market value for the land (interviews 8, 14).

Agricultural production in Las Cañas was based on potato. However, respondents consistently pointed out that high production and transport costs, low market prices, and low technical input available, made potato production economically unviable. Increased climatic variability has compounded economic changes, since it increases the investment risk inherent in agriculture (focus group, interview 2). Peasants have therefore refrained from producing potatoes for sale, and mostly grow them for subsistence. Households in Las Cañas usually possessed between two to four heads of cattle for milk production, along with poultry and goats. For most households, the occasional sale of produce and daily sale of raw milk (at about 500 Colombian pesos per bottle, equivalent to about $\$ .2$ U.S. dollars) to a middleman was the only regular monetary income. Households either cultivated land that they possessed or, more infrequently, rented it, and land was not managed on a communal basis. Despite important outmigration rates, there appeared to be little influx of remittances. Entire households had moved away recently, and when migration had involved only a few members in a households, most individuals were not in the position to send remittances since they lacked the skills 
to find well paid professional jobs or were unemployed (interviews 1, 4). Most residents of Las Cañas have mortgaged their property to fund agricultural activity (interview 8).

Las Cañas has experienced decreasing population for the last twenty years. While official figures were not available, local residents estimated that the population had more than halved in the last twenty years due to outmigration and decreased fertility rates. Immigration was reported only with reference to marriages of residents with partners of neighbouring areas. Estimates placed the number of households and of residents in 2014 between twenty-five (focus group, interview 4) and thirty-seven (Alcaldía de Sogamoso, 2013), and around 150 respectively. The number of children enrolled in the local primary school decreased from around seventy in the 1990s, to forty in the early 2000s, and thirteen in 2014 (interview 4). Depopulation and low fertility rates resulted in an old demographic profile of residents.

Las Cañas can be described as a mestizo population with no formal or informal indigenous system of communal organization. In fact, while informal institutions as described in the previous section reproduce social networks and belonging to the vereda, as noted by Fals Borda (2006) the basic social unit is the household, not any notion of community.

There was no formal peasant organization, either productive, political or of another nature, in Las Cañas, with exception of the Junta de Acción Comunal (Communal Action Board). However, the respondents appeared not to play a significant role in the vereda; Las Cañas appeared to have no formal leaders. In fact, the primary school plays an aggregative role since parents were occasionally involved in educational activities. The school has also been the location where the few gatherings took place, such as the monthly health visit day. There was no stable religious presence in the vereda, although some suggested that Catholicism once exerted a stronger influence in Las Cañas (focus group, interviews 1, 7). 
Little technical innovation was observed in Las Cañas, and agriculture was practiced mostly manually (focus group). While some peasants had attempted aquaculture or the cultivation of different crops than potatoes (berries, peas, carrots), they were generally unsuccessful economically and culturally, often met by general suspicion as a deviation from the local peasant identity strongly founded in potato farming (focus group, interviews 6, 9). Various governmental development agencies and businesses have carried out a range of initiatives, such as the Mujeres Emprendedoras (Businesswomen) programme. These interventions have had little impact on Las Cañas and have generally been met with scepticism by peasants who disliked the patronizing, aggression, and contempt often shown by development officers. Most importantly, the development interventions sought to create and diffuse a utilitarian rationality to support micro agro-businesses, which was at odds with peasants' traditional household model and livelihood preferences.

While high production costs, low market prices, and increased climatic variability made farming a risky livelihood option, exposure to urban and 'modern' lifestyles has further contributed to making farming a non-attractive income source. Nevertheless, despite the hardship of a life in the vereda, most residents and out-migrants alike strongly appreciated the freedom, independence, and the contact with the natural environment that this life allowed them to have. These were considered essential elements of well-being and identity (interviews 12,16) contrasted with life in the city. In fact, although outmigration was common, it was usually experienced as an uprooting and as a forced necessity (interview 9).

Exposure to modern urban lifestyles mostly occurred through NGO and government visits, the radio and, in some households, television. Visits to Sogamoso or other cities were occasional (interviews 9, 12) and the cost of public transport was a barrier to mobility for many residents (interview 11). Education played an important role exposing children to external influences; according to peasants and key informants, the primary school in the area did not prepare children for a professional life in farming (interviews 2, 3, 4, 9). Neither did the secondary school in the nearby locality of El Crucero, 
which has been attended by an increasing number of children of Las Cañas since a school transport service was introduced free of charge. Thus, education may have given the illusion of preparing young people for a professional life in the city rather than in the vereda, and this acted as a further pull factor. While temporary or seasonal migration was a common livelihood strategy in nearby communities (interview 1), in Las Cañas outmigration was mostly permanent. Furthermore, it was through secondary education that many young people of Las Cañas have left, and this has come to be an established biographical model for young people to follow (interview 3).

\section{Results and discussion}

This section presents the findings on institutional change and continuity in Las Cañas (sections 6.1 and 6.3, respectively), and employs the theoretical background offered by evolutionary theories of institutional change and theories of institutional continuity to interpret and discuss the findings (sections 6.2 and 6.4). An overview of the findings on institutional change and continuity in the study area is provided in Table 2 . 
Table 2. Overview of observed change or continuity of informal institutions and related natural model.

\begin{tabular}{lll}
\hline Informal institutions & Reference & Finding \\
\hline Egalitarian land inheritance & Fals-Borda (2006) & Continued \\
Intergenerational sharecropping & Fals-Borda (2006) & Continued \\
In-kind payment of day labourers & Gudeman and Rivera (1990) & Almost disused \\
Work exchange reciprocity (mano vuelta) & Gudeman and Rivera (1990), De los Rios and & Partly disused \\
& Almeida (2010) & \\
Gender-based division of labour & Fals-Borda (1955), Gudeman and Rivera (1990) & Partly changed \\
Barter, gift & Torres Guevara (2002) & Mostly continued \\
Festivities & Fals-Borda (1955), Gudeman and Rivera (1990) & Disused \\
\hline Natural model and ethos & & \\
\hline Vital energy & Gudeman and Rivera (1990), Gudeman (2012) & Continued \\
Ethos & Fals-Borda (1955), Gudeman (2012) & Continued \\
\hline
\end{tabular}

\subsection{Institutional change in Las Cañas}

The data collected suggest that four of the informal institutions considered in this study showed signs of change or disuse (Table 2). Among these were the informal institutions that regulated the exchange and allocation of labour. Peasants would hire day labourers for help on particularly labourintensive tasks. However, respondents reported that many day labourers stopped accepting the traditional in-kind payment preferring cash instead (focus group, interview 11). In response to this change most peasants had begun to refrain from hiring day labourers (focus group). Peasants perceived the refusal of in-kind payments and the request for cash payment for labour as unacceptable, since it cut into savings and the flow of vital energy, which is the bond of social relations. The very requests were perceived as cultural defiance of fundamental social relations embodied in informal institutions (focus group). 
Similarly, the reciprocal work exchange (mano vuelta) had largely gone into disuse. While peasants stated that they continued to practice the mano vuelta (interviews 3,9 ) the reduction of land that was farmed-as a consequence of the move from cash crop to subsistence farming-had made the mano vuelta of little use since the labour available within a household was often sufficient to manage the land available (focus group, interview 11).

Household labour allocation has also changed. Traditionally, from a young age, people in Las Cañas carried out important tasks in the household, such as tending animals and helping the elderly during harvest (focus group, interview 3 ). These tasks usually coexisted with attendance at school. However, with young people increasingly attending secondary school outside the vereda, observations suggested that women and men in the household had reallocated labour to cover for the reduced availability or absence of young people's labour. As a consequence, women were expected to carry out tasks that were not traditionally their responsibility.

“Here women go to work [in the fields]. In the past, they didn't. [...]. Some must work hard [in the fields]" (focus group).

Other influences may have changed the gender-based division of labour. Among these women's participation in education, which has increased in the last decades (interviews 1, 4), and, possibly, the government interventions such as the 'Businesswomen' program, which while not resulting in actual micro enterprises, may have encouraged young women to take a more prominent decisionmaking role in the household (interview 3).

Moreover, younger women in the vereda began to assemble at the school to discuss current issues. In the words of an out-migrant:

"I would always do some small jobs. We [the women], talked and, that's it, all together we would do that. For example things at the school, because all people in the vereda benefit [from work done] there. So, yes, all [women] would talk and meet up" (interview 9) 
However, it was not possible to ascertain how widespread these changes were and, while similar empowerment dynamics have been observed in other peasant communities in the Andes (Bendini and Steingreger 2011), key informants partly disagreed on the extent to which women have taken more equal stand with men in the study region (interviews 1,4$)$.

Finally, festivities had gotten prohibitively expensive since residents often funded them themselves, and did not have expendable income since the turn to subsistence farming. As noted by a peasant:

"First, we don't have resources, because the inhabitants who live here ... we are very few and there aren't resources" (focus group).

\subsection{Processes leading to institutional change in Las Cañas}

The data suggest that the institutional change, or, more frequently, disuse, observed in Las Cañas (Table 2) was a response to two interconnected pressures, namely the turn to subsistence agriculture and the thinning social networks. Informal institutions had changed, or had been disused, to allow for the pursuit of livelihood in the face of a changing context in which the market had outcompeted cash crop production, and in which labour was scarce due to depopulation or costly due to disuse of in-kind payment. Subsistence agriculture was not an attractive livelihood option for young people in the vereda (focus group, interview 3), and increased climatic variability had increased the risk of crop loss. Outmigration to the city had become for many the most attractive option, which had caused thinning social networks, had reduced the availability of reciprocal labour, and changed the demographic profile of the population in Las Cañas. These effects, coupled with the reduced income levels caused by the turn to subsistence agriculture, appeared to limit the capacity to adapt and to develop alternative livelihood options in the vereda.

These findings mirror those of other Andean studies in which out-migration was found to weaken social networks and to be a source of cultural and institutional change (Gray, 2009; Gilles et al., 2013). Contrary to what some scholars found (Bebbington, 2000; Bendini and Steinbreger, 2011), 
outmigration in Las Cañas was not an adaptive strategy adopted to complement income from farming activities, but a forced choice that indicated the difficulty of peasants reproduce the household economy. Moreover, to the extent that informal institutions have helped build adaptation in the past, and similarly to what was observed by Eriksen and Selboe (2012:159), the "reduction in the number of people involved in farming may be putting the flexibility of social networks and practices of collaboration under pressure, potentially undermining adaptive capacity to climate change".

It is interesting to stress that the disuse of institutions, rather than institutional change, was more frequently observed, which can be explained through evolutionary institutional change theories. Institutional selection appeared to have occurred mostly through s- and partly through m-selection, with little evidence of p-processes (Burns and Dietz, 1992). Regarding s-selection, the disuse of informal institutions appeared to be a strategy to maintain their consistency with the fundamental natural model and ethos. Rather than challenging their natural model by modifying the institutions, peasants appeared to pre-empt potential cultural inconsistencies by disusing, rather than modifying the institutions. For example, festivities, which were costly detractions from the base, fell into disuse rather than being held differently. In sum, s-selection has resulted in endogenous selection of institutions. Moreover, regarding $\mathrm{m}$-selection, increased climatic variability has increased the risk associated with farming. However, m-selection had mostly indirectly affected informal institutions by acting as an additional factor for out-migration, resulting in changes in demographic composition, social network density, and labour availability.

\subsection{Institutional continuity in Las Cañas}

The data suggest that most of the informal institutions and the natural models and ethos that characterise peasantry in this region have persisted in the face of environmental, economic and social disturbances (Table 2). Egalitarian land inheritance and intergenerational sharecropping are 
informal institutions that regulate younger generation's access to land. Intergenerational sharecropping, however, was interrupted when young men out-migrated (interviews 3,11 ). Similarly to other cases in Colombia (Torres Guevara, 2002), observations suggest that barter and other exchanges of goods (e.g. produce, eggs, milk) in the form of gifts also persisted, although there was no evidence of this being a substantial livelihood component for households except for singleheaded (male or female) elderly households, which may have been almost totally dependent on transfers of food from younger relatives.

Evidence also exists that the natural model of vital energy and the traditional peasant ethos observed in the past in this region persists among residents of Las Cañas in the face of exogenous changes. Peasants appeared to consider the household as the fundamental social unit, and this was reflected in life histories that were narrated from the perspective of the household, not of individuals or communities (interviews 4, 9, 11). Furthermore, that peasants have prioritised their household over the community represents a barrier for the setting up and sustaining of formal collective associations. A key informant illustrated that:

\footnotetext{
"35 years ago [...] we managed to set up 238 peasant cooperatives [in the region] and 237 of these failed. Only one survived. And all [failed] because of the attitude of the members towards individual forms [of organization]. [They] could not manage any associative form of production" (interview 6).
}

Thus, in contrast with cases in which informal institutions have supported communal adaptation strategies, such as storage, economic diversification, and land pooling (Mayer, 2002; Agrawal et al., 2008), Las Cañas is a case in which despite the persistence of some reciprocity institutions, no substantial communal, or cooperative production was implemented.

Peasants in Las Cañas perceived themselves as marginal and continue to mark their difference from the city. This was apparent in the vocabulary used by the respondents, who, as found by Gudeman 
and Rivera (1990), used the word centro ("centre") when referring to the city, to indicate not only a spatial differentiation, but also a differentiation from the market. Moreover, in the perspective of peasants living in Las Cañas, the "centre" was usually associated with negative attributes, such as lack of freedom, dependency on money and commodified social relations, a lack of social connections, and lack of understanding of the natural environment (focus group, interviews 8,12 , $13,15,16)$. Therefore, the freedom of the vereda was to a great extent freedom from utilitarian logic and the market as a mechanism for social organization. In the words of respondents:

"Here in the rural area one lives better. I don't like life in the centre [...] If one does not have money there one cannot even get out. I feel there like someone who is in prison" (focus group).

"It's not nice to live in the centre. They won't know if it will rain or not" (interview 12).

People in Las Cañas not only expressed a strong attachment to and respect of the physical environment (focus group, interviews $3,4,6,9,12$ ), but also used a vocabulary that reflects the natural model of vital energy. Both adults and children employ anthropomorphic metaphors of aging, resting, and flows of strength that can be re-conducted to the model of vital energy with respect to soil and labour, and point to a circular and long-term time perspective:

"I think that to soil happens the same as to the human being; it gets old, one must remodel it, I think" (focus group).

"Sometimes yes [we resort to the mano vuelta], but most people [nowadays] sow little. In the past yes, one would share fuerza [vital energy] to help each other out. But now not anymore" (interview 11).

"[...] this soil won't give anything to seeds [...]. Now one cannot sow potato. One needs to wait some time [...] because the earth must rest a bit" (interview 3; respondent reporting children's knowledge of soil). 
Peasants in Las Cañas shared an ethos of sufficiency and austerity, characterised by making savings, enduring hardship, being content with low standards of living, albeit aspiring to better and more stable ones, and appreciating the beauty and purity of the physical environment. Most importantly, consistently with the natural model of vital energy, people in Las Cañas expressed little desire for material accumulation, and did not seek monetary gains. For example, in discussing tourism as an alternative source of income, a respondent explicitly stressed that this should "not [be] for people to say they get a lot of money. No; the right amount" (interview 12). This did not prevent peasants from aspiring to better standards of living, especially in relation to housing, health education and transport infrastructure (interviews 8-16). Nevertheless, the respondents usually associated better and more stable life conditions as the long-term result of unending struggle. Peasants defined better life conditions in terms of the use-value of goods, rather than monetary value, thus manifesting the pursuit of the fundamental aim of increasing the household's base:

"I had lived there until I had my children. I was one of those who would never leave that land [Las Cañas], who would take care of it, get my house better day after day, improve my farm day after day, live well" (interview 9).

Furthermore, while peasants often expressed the desire for financial or infrastructural support from the government, this was not to substitute for farming. Rather, peasants saw in external governmental support the possibility to enable them to face market disturbances and continue to engage in traditional livelihood activities-particularly potato farming-a defining characteristic of peasants in this region. In effect, many respondents resented the lack of government support not only because it showed the marginality of the vereda, but also because such lack of intervention was perceived as the reason why peasants could not engage in the farming activities that had historically defined their identity in Las Cañas (interview 8).

Peasants in Las Cañas also maintained a reserved nature and a general distrust of anything external to the vereda, such as development officers, the conservation agency, middlemen or local 
politicians. Exogenous influences are perceived as threats of expropriation or scams due to historical cases of land expropriation for conservation (interviews 8, 12), or in development projects that require placing savings in bank accounts in the city outside of the perceived direct owner's control (focus group). Similarly, peasants were wary of local politicians visiting the vereda only in time of elections to "buy" their vote through promises that usually remained unattended (interviews 8, 10).

A social stigma was associated to being a peasant, as noted by an out-migrant:

"I believe one of the things that most affects peasant identity resides in mass media, because in Colombia the peasant is poor, stinks, does not shower, is rude [...] (interview 4).

Key informants confirmed that peasants were usually treated patronizingly and with contempt by development officers or representatives of private businesses (interviews 1, 2, 4, 14), confirming earlier findings in the literature (Fals-Borda, 1955; Forero, 2010). In the words of a resident of Las Cañas:

\footnotetext{
"The projects ... for example the Municipality with these projects on water [...]. They come to exercise their power on us. It's a matter of time and they will spoil and throw everybody out from here" (interview 12).
}

"People [i.e. peasants] are well aware that most of what the State gives is a way to use them"

"The social workers who go [to Las Cañas]; their form of interaction is aggressive" (interview 4).

\subsection{Processes leading to institutional and cultural continuity in Las Cañas}

The data suggest that institutional continuity in Las Cañas resulted from three sources: selective outmigration, conformist intergenerational transmission, and everyday resistance. These sources are 
generally endogenous and operated through s- and m-selection (Burns and Dietz, 1992), and resulted in increased institutional integration and cultural homogeneity.

Outmigration was a phenomenon that did not invest all households in Las Cañas evenly. Outmigrants were those who had attempted different livelihood options (e.g. aquaculture or alternative crops) and failed, and those who had not liked the austerity and hardship of the vereda. Outmigrants narrated histories of attempted innovation, while residents of Las Cañas showed little propensity to attempt alternatives and tended to discard the possibility that things may be done differently.

"Those who have left, they have done it because of the economic difficulties. But they have also left because they don't adapt to the way of life in the vereda. Life in the vereda is not easy [...] but there's a lot one can do" (interview 16).

"I did not move [to the city] because I was poor, nor because I was bored. I did not move because I did not appreciated my land, never. With the neighbours things were fine ... one can have some problems, but I did not move because of this ... nor because of the violent conflict. [...] I moved because [...] I started to think about education, the school years, what education I received. And I started to think that my son would get the same and that I had to move to give an educational opportunity to my son" (interview 9).

As a consequence of selective outmigration, people who stayed in Las Cañas tended to be those who did not have the resources or agency to seek alternatives, or genuinely appreciated the "vereda way of life" (interview 16), which both residents and outmigrants of Las Cañas consistently associated with natural beauty, hardship, sufficiency, freedom and independence, tradition, and farming (interviews $2,4,9,16)$. Thus, selective outmigration appears to have increased homogeneity and institutional and cultural integration and favour institutional continuity, rather than change. 
A second source of institutional and cultural continuity was represented by conformist intergenerational cultural transmission, which is a known source of cultural persistence (Burns and Dietz 1992). Most knowledge about the physical environment, farming and peasant culture had been transmitted from older to younger generation through word of mouth or practical experience, rather than in school, since farming was not a part of the local school curriculum. Informal institutions and cultural models were therefore mostly acquired experientially through participation of younger people in household activities:

"[The children] have their knowledge [of the natural environment in the vereda], but this knowledge is thank to the grandfathers, the fathers" (interview 3).

Finally, institutional and cultural continuity appeared to result from practices of everyday resistance to a range of forms of exploitation, expropriation, and marginalization. In a context in which organized collective action has historically lacked and has more recently become difficult by shrinking social networks (due to outmigration), peasants have responded to exogenous forces of oppression and exploitation by enacting forms of cultural resistance at the individual level. They have resisted by bantering politicians, downplaying the effects of conservation projects and reaffirming the validity of traditional (experiential) knowledge of the natural world, and refusing to participate in economic development schemes. Still, everyday resistance did not exclusively entail outright opposition to external influences, but a process of active renegotiation. Particularly, while the training or development programs promoted by governmental and non-governmental agencies had generally not succeeded in Las Cañas, they had influenced peasant culture, particularly with respect to instilling notions of 'environmental protection' (focus group, interview 8). The importance of 'traditional' elements in the cultural underpinnings of peasant resistance, such as norms of reciprocity, the right to subsistence and millenarian beliefs, has been discussed by Scott (1976) and Taussig (1980). By negotiating, re-enacting and reaffirming the validity of informal institutions and 
ethos, peasants have resisted the homogenizing force of markets and the patronizing and stigmatizing pressure of government, development, and conservation agencies.

Thus, natural models in Las Cañas constitute a social attractor (Abel et al., 2006) that endogenously selected institutional variations, informed institutional selection, and embodied the place identity and memory of the vereda. However, while in other cases it has been shown that culture contributed to building adaptive capacity in rural communities (von Heland and Folke, 2014), in Las Cañas, informal institutions did not support adaptive capacity, but rather lock the system in a vulnerable state, which is reflected in farmers foreseeing the disappearance of Las Cañas (focus group, interview 12). Cultural and material conditions produce an identity lock-in (Wilson, 2012), whereby the vereda is seen to be characterised by natural beauty, hardship, sufficiency, freedom and independence, tradition, and farming, while people living in this place share ways of life and being and identify as peasants and potato growers. Las Cañas appears to be trapped in a dynamic of cultural continuity that resist the forced transformation toward industrial agriculture but, also because of the erosion caused by modernising pressures, does not support alternatives to such form of 'development' as those observed for example in other parts of the Andes where livelihoods where informed by reassembled 'traditional' and 'modern' cultural elements (Bebbington, 2000; Cleaver, 2001; Arias, 2005; Espinosa, 2009).

\section{Conclusions}

There is contrasting evidence on the capacity of peasant communities in the Colombian Andes to adapt to simultaneous environmental and economic disturbances. This study employed evolutionary institutional change theories and theories of institutional continuity to enhance the understanding of current adaptation dynamics in a region and population that are often overlooked due to their remoteness and marginality. This study focused on informal institutions and the natural models that 
legitimize them. Informal institutions have not only historically structured human-environment interactions in the Andes, but have also been fundamental to adaptation in a context in which there exists a lack of formal institutions and organizations that could manage adaptation to environmental change and variability, or coordinated responses to economic changes.

This study is based on a particular study site and time, and therefore offers limited basis for generalization. With this caveat, though, this paper suggests that institutions may persist despite substantial contextual changes, albeit in a continuous relation with other influences, and identifies the sources of institutional continuity: selective outmigration, conformist intergenerational transmission, and everyday resistance. Las Cañas was characterised by a substantial institutional continuity. Most of the informal institutions and cultural models that characterise peasantry in this region have persisted in the face of environmental and economic disturbances. Exogenous disturbances have activated a turn to subsistence agriculture and the thinning social networks in Las Cañas, which have led to the disuse of some informal institutions, but which have also resulted, through selective outmigration, conformist intergenerational transmission, and practices of everyday resistance, in the continuity of most informal institutions and of the natural model and ethos that sustains them. Thus, the natural model represents the social attractor of endogenously selected institutional variations, informs the perception and responses to exogenous disturbances, and embodies the identity and memory of the vereda.

This study exposes some of the potential tensions between resilience, cultural diversity, and transformation. In Las Cañas, informal institutions and cultural models largely persisted despite, and partly as a response to forced transformation towards industrial agriculture. In this sense, Las Cañas can be considered a case of defence of cultural diversity and resistance to cultural (and consequently economic and social) homogenization. However, the modernising forces to which the vereda is exposed undermine peasants' capacity to pursue an active transformation towards desired futures; the vereda is eroded through outmigration, the impossibility to compete in the agricultural markets 
and the compounding effect of climatic variability that increases the risk associated with farming. Under these conditions, informal institutions cannot support alternative livelihoods, which leads to a relentless disappearance of Las Cañas.

Future research should explore under what conditions institutional adaptation is observed and when it is related to increased resilience. How are transformability, social-ecological resilience and cultural diversity related? Particularly, can adaptive capacity and resilience be built while preserving cultural diversity and active transformation towards desired and place-specific futures? These questions may be important in many other marginal rural places in the Andes.

\section{Acknowledgments}

My sincere gratitude goes to the people of Las Cañas and the key informants for participating in this study. I extend my earnest gratitude also to Sandra Riveros, the Fundación Jischana Huitaca (particularly Jenny Soler and Jaime Suzunaga), Juan David Reina, and Stefania Gallini for their support in various phases of field work, and to Carlos del Cairo, and Andrew Ainslie for comments on an earlier version of this manuscript. Earlier versions of this paper were discussed in research seminars at the Political Ecology Research Group (Javeriana University), the Centre for Systems Integration and Sustainability (Michigan State University), the School of Agriculture, Policy and Development (University of Reading). I received very useful feedback on all these occasions. Finally, I am deeply grateful to the British Academy and Leverhulme Trust for funding this study (grant number SG122528). 


\section{References}

Abel, N., Cumming, D.H.M., Anderies, J.M., 2006. Collapse and Reorganization in Social-Ecological Systems: Questions, Some Ideas, and Policy Implications. Ecology and Society 11(1), 17.

Agrawal, A. et al., 2012. Climate Policy Processes, Local Institutions, and Adaptation Actions: Mechanisms of Translation and Influence. Wiley Interdisciplinary Reviews: Climate Change 3(6), 565579.

Agrawal, A., McSweeney, C., Perrin, N., 2008. Local Institutions and Climate Change Adaptation. Washington DC, USA: World Bank.

Aoki, M., 2007. Endogenizing Institutions and Institutional Changes. Journal of Institutional Economics 3(1), 1-31.

Arias, E., 2005. Agricultural Market Reforms and Potato Farmers' Strategies in the Pueblo Llano Valley, Venezuelan Andes. Mountain Research and Development 25(4), 357-64.

Bebbington, A., 2000. Reencountering Development: Livelihood Transitions and Place Transformations in the Andes. Annals of the Association of American Geographers 90(3), 495-520.

Bendini M.I., Steinbreger, N.G., 2011. Persistencia campesina en el norte de la Patagonia: Movilidades espaciales y cambios en la organización social del trabajo. Cuadernos de Desarrollo Rural 8(66), 125-151.

Boyd, E., Folke, C. eds., 2011. Adapting institutions: Governance, complexity and social-ecological resilience. Cambridge University Press.

Burns, T. R., Dietz, T., 1992. Cultural Evolution: Social Rules Systems, Selection and Human Agency. International Sociology 7(3), 259-83. 
Cárdenas, M., Rodríguez, M. (Eds.). (2013). Desarrollo Económico y adaptación al cambio climático. Bogotá: Frescol and Foro Nacional Ambiental.

Casson, M. C., Della Giusta, M., Kambhampati, U. S., 2009. Formal and Informal Institutions and Development. World Development 38(2), 137-41.

Cleaver, F., 2001. Institutional Bricolage, Conflict and Cooperation in Usangu, Tanzania. IDS Bulletin $32,26-35$.

Cleaver, F., 2012. Development Through Bricolage: Rethinking Institutions for Natural Resource Management. London: Routledge.

Comerci, M. E., 2012. Estrategias campesinas, tensiones y redefiniciones en espacios revalorizados por el capital. Cuadernos de Geografía 21(1), 131-146.

Cruz, E., 2014. Dignidad en movimiento. El ascenso de la movilización social en Colombia (20102014). Confluenze 6(2), 241-275.

David, P. A., 1994. Why are institutions the carriers of history? Path dependence and the evolution of conventions, organizations and institutions. Structural Change and Economic Dynamics 5(2), 20520.

De Los Rios, J. C., Almeida, J., 2010. Percepciones Y Formas de Adaptación a Riesgos Sociambientales En El Páramo de Sonsón, Colombia. Cuadernos de Desarrollo Rural 7(65), 109-27.

Dietz, T., Burns, T R., 1992. Human Agency and the Evolutionary Dynamics of Culture. Acta Sociologica 35, 187-200.

DNP-BID., 2014. Impactos Económicos del Cambio Climático en Colombia - Síntesis. Bogotá, Colombia.

Douglas, M., 1986. How institutions think. Syracuse University Press. 
Eakin, H., 2005. Institutional change, climate risk, and rural vulnerability: Cases from Central Mexico. World Development 33(11), 1923-1938.

Eriksen, S., Selboe, S., 2012. The social organisation of adaptation to climate variability and global change: The case of a mountain farming community in Norway. Applied Geography 33, 159-167

Escobar, A., 1995. Encountering development: The making and unmaking of the Third World. Princeton University Press.

Espinosa, C., 2009. Negotiating Landscapes, Survival, and Modernity: Goats, Migration, and Gender in the Arid Lands of Northern Peru. Culture \& Agriculture 31(1), 39-48.

Fals-Borda, O., 1955. Peasant society in the Colombian Andes: a sociological study of the Saucio. University of Florida Press

Fals-Borda, O., 2006. El hombre y la tierra en Boyacá. Universidad Pedagógica y Tecnológica de Colombia.

Feola, G., Agudelo Vanegas, L. A., Contesse Bamón, B. P., 2015a. Colombian Agriculture under Multiple Exposures: A Review and Research Agenda. Climate and Development 7(3), 278-292.

Feola, G., 2013. What (science For) Adaptation to Climate Change in Colombian Agriculture? A Commentary on 'A Way Forward on Adaptation to Climate Change in Colombian Agriculture: Perspectives towards 2050 ' by J. Ramirez-Villegas, M. Salazar, A. Jarvis, C. E. Navarro-Valcines. Climatic Change 119(3-4), 565-74.

Feola, G., 2015. Societal transformation in response to global environmental change: a review of emerging concepts. AMBIO 44(5), 376-390. 
Feola, G., Lerner, A., Jain, M., Montefrio, M.J.F., Nicholas, K.A. 2015. Researching farmer behaviour in climate change adaptation and sustainable agriculture: lessons learned from five case studies. Journal of Rural studies, 39:74-84.

Forero, J., 2010. El campesino colombiano: entre el protagonismo económico y el desconocimiento de la sociedad. Pontificia Universidad Javeriana.

Forero, J., 2013. The Economy of Family Farming Production. Cuadernos de Desarrollo Rural 10(70), 27-45.

Forsyth, T., Evans, N., 2013. What is Autonomous Adaption? Resource Scarcity and Smallholder Agency in Thailand. World Development 43, 56-66.

Gilles, J. L., Thomas, J. L., Valdivia, C., Yucra, E S., 2013. Laggards or Leaders: Conservers of Traditional Agricultural Knowledge in Bolivia. Rural Sociology 78(1), 51-74.

Gray, C. L., 2009. Environment, Land, and Rural Out-Migration in the Southern Ecuadorian Andes. World Development 37(2), 457-68.

Gudeman, S., Rivera, A., 1990. Conversations in Colombia. Cambridge University Press

Gudeman, S., 2012. Vital Energy. The Current of Relations. Social Analysis 56(1), 1-17.

Hay, I., 2010. Qualitative research method in Human Geography. Oxford University Press.

Hristov, J., 2005. Indigenous Struggles for Land and Culture in Cauca, Colombia. Journal of Peasant Studies 32(1), 88-117.

Jackson, P., Russell, P., 2010. Life history Interviewing. In: Delyser et al. eds. SAGE Handbook of Qualitative Geography. SAGE, pp 172-192. 
Jütting, J., Drechsler, D., Bartsch, S., de Soysa, I., 2007. Informal Institutions. How Social Norms Help or Hinder Development. OECD.

Kingston, C., Caballero, G., 2009. Comparing Theories of Institutional Change. Journal of Institutional Economics 5(2), 151-80.

Mayer, E., 2002. The Articulated Peasant: Household Economies in the Andes. Westview Press.

Mitchell, W. P., 1988. Peasants on the Edge: Crop, Cult, and Crisis in the Andes. University of Texas Press.

Mitchell, R. B., 2008. Evaluating the Performance of Environmental Institutions: What to Evaluate and How to Evaluate It? In: Young, Oran R., Leslie A. King, and Heike Schroeder, eds. (2008). Institutions and environmental change: principal findings, applications, and research frontiers. MIT Press, 79-114.

North, D., 1990. Institutions, Institutional Change and Economic Performance. Cambridge: Cambridge University Press.

Ostrom, E., Gardner, R., Walker, J., 1994. Rules, Games, and Common-Pool Resources. University of Michigan Press.

Peralvo, M., Postigo, J., López, S., 2010. Adaptación en Sistemas Productivos Andinos a los efectos del Cambio Climático: revisión y síntesis del estado del conocimiento. Lima-Quito: CONDESAN.

Petras, J., Veltmeyer, H., 2002. The Peasantry and the State in Latin America: A Troubled Past, an Uncertain Future. The Journal of Peasant Studies 29(3-4), 41-82.

Postigo, J. C., Young, K. R., Crews, K. A., 2008. Change and Continuity in a Pastoralist Community in the High Peruvian Andes. Human Ecology 36(4), 535-51.

Plan de Ordenamiento Territorial (POT) Sogamoso. Alcaldia de Sogamoso. 
Poteete, A. R., 2014. How Far Does Evolution Take Us? Comment on Elinor Ostrom's: Do Institutions for Collective Action Evolve? Journal of Bioeconomy 16, 91-98.

Ramirez-Villegas, J. et al., 2012. A way forward on adaptation to climate change in Colombian agriculture: perspectives towards 2050. Climatic Change 115(3-4), 611-628.

Raynaut, C., 2001. Societies and Nature in the Sahel: Ecological Diversity and Social Dynamics. Global Environmental Change 11(1), 9-18.

Ribot, J., 2014. Cause and response: vulnerability and climate in the Anthropocene. The Journal of Peasant Studies 41(5), 667-705.

Rist, S., 2000. Linking Ethics and the Market. Campesino Economic Strategies in the Bolivian Andes. Mountain Research and Development 20(4), 310-315.

Sarmiento, L., Monasterio, M., Montilla, M., 1993. Ecological Bases, Sustainability, and Current Trends in Traditional Agriculture in the Venezuelan High Andes. Mountain Research and Development 13(2), 167-176.

Scott, J., 1986. Everyday Forms of Peasant Resistance. Journal of Peasant Studies 13(2), 5-35.

Searle, J. R., 2005. What Is an Institution? Journal of Institutional Economics 1(1), 1-22.

Shanin, T., 1973. The Nature and Logic of the Peasant Economy 1: A Generalisation. Journal of Peasant Studies 1(1), 63-64.

Stadel, C H., 2008. Vulnerability, Resilience and Adaptation: Rural Development in the Tropical Andes. Pirineos 163, 15-36.

Taussig, M., 1980. The devil and commodity fetishism in South America. University of North Carolina Press. 
Tengö, M., on Heland, J., 2012. Adaptive capacity of local indigenous institutions: the case of the taboo forests of southern Madagascar. In: Boyd, E., Folke, C. (eds.) (2011). Adapting institutions: Governance, complexity and social-ecological resilience. Cambridge University Press, pp 75-100.

Ternström, I., 2012. Adapting to change: tracing farmers' responses to disturbances in irrigation systems in Nepal. In: Boyd, E., Folke, C. (eds.) (2011). Adapting institutions: Governance, complexity and social-ecological resilience. Cambridge University Press, pp 75-100.

Torres Guevara, L. E., 2002. Autoconsumo y reciprocidad entre los campesinos andinos: caso Fómeque. Cuadernos de Desarrollo Rural 28, 80-98.

Underdal, A., 2008. Determining the Causal Significance of Institutions: Accomplishments and Challenges. In: Young, O.R., King, L.A., Schroeder, H. (eds.) (2008). Institutions and environmental change: principal findings, applications, and research frontiers. MIT Press, 49-70

von Heland, J., Folke, C., 2014. A social contract with the ancestors-culture and ecosystem services in southern Madagascar. Global Environmental Change 24, 251-264.

Wegerich, K., 2001. Institutional Change: A Theoretical Approach. London: School of Oriental and African Studies. Occasional Paper No 30.

Wilson, G., 2012. Community resilience and environmental transitions. Routledge.

Young, K. R., Lipton, J. K., 2006. Adaptive Governance and Climate Change in the Tropical Highlands of Western South America. Climatic Change 78(1), 63-102.

Young, O. R., King, L. A., Schroeder, H., eds., 2008. Institutions and environmental change: principal findings, applications, and research frontiers. MIT Press. 